\title{
A Capacity Design Procedure for Columns of Steel Structures with Diagonals Braces
}

\author{
M. Bosco ${ }^{*}$, A. Ghersi, E.M. Marino and P.P. Rossi \\ Department of Civil Engineering and Architecture, University of Catania, Italy
}

\begin{abstract}
According to modern seismic codes, in concentrically braced frames the seismic input energy should be dissipated by means of the hysteretic behaviour of braces while all the other members (i.e. beams and columns) have to remain elastic. Accordingly, the design internal forces of braces are determined in these codes by elastic analysis of the structure subjected to seismic forces obtained by the design spectrum. The internal forces of the non-dissipative members, instead, are calculated by means of specified rules for the application of capacity design principles. According to some recent numerical analyses, the yielding or buckling of columns may take place before braces achieve their axial deformation capacity. This paper investigates the reasons of this unsatisfactory behaviour and proposes technological suggestions and a design procedure to improve the seismic performance of columns of building structures with diagonal braces.
\end{abstract}

Keywords: Capacity design, columns, nonlinear dynamic analysis, concentrically braced frame, seismic design, steel structure.

\section{INTRODUCTION}

Concentric braces are known to be very effective structural elements that can provide lateral stiffness and strength in steel building structures. Furthermore, concentrically braced frames are very commonly used in earthquake-prone countries where building frames have to endure large lateral forces.

For each structural type, modern seismic codes define structural members that should dissipate energy during the ground motion by means of their hysteretic behaviour (dissipative members) and members that should remain elastic (non-dissipative members). In concentrically braced frames, according to Eurocode 8 (EC8) [1] as well as other modern seismic codes [2-6], braces are the dissipative members, while all the other members (i.e. beams and columns) should remain elastic. Accordingly, in these codes the design internal forces of braces are determined by elastic analysis of the structure subjected to seismic forces obtained by the design spectrum. The internal forces of the non-dissipative members, instead, are calculated by means of specified rules for the application of the capacity design principles. In particular, EC8 suggests that the design internal forces of columns should be calculated by amplification of the internal forces produced in columns by the abovementioned elastic analysis. The terms that allow this amplification take into account both the material overstrength and the brace overstrength.

In building structures with concentrically braced frames, the structural system is conceived so that the seismic force is resisted by a few braced frames while the other frames sustain gravity loads only. The numerical models commonly used for the design of these structures include only the

*Address correspondence to this author at the Department of Civil Engineering and Architecture, University of Catania, V. le A. Doria 6, 95125 Catania, Italy; Tel: +39 095 7382274; Fax: +39 095 7382298;

E-mail: mbosco@dica.unict.it braced frames and basically neglect the bending moment in structural members [7]. These numerical models are consistent with EC8, which defines concentrically braced frames as "those in which the horizontal forces are mainly resisted by members subjected to axial forces". However, the bending moments in columns (those of the braced frame as well as gravity columns) may achieve significant values due to the lateral displacement demand concentration when the braced frame overcomes its elastic limit and the braces experience large inelastic deformation. According to some recent numerical analyses, these bending moments combined with axial forces generally exceeding those predicted by code provisions may cause yielding or buckling of columns before braces achieve their axial deformation capacity [8-10].

This paper proposes technological suggestions and design procedures to improve the seismic performance of columns of building structures with diagonal braces. In particular, it is suggested that columns of the braced frame, which have to sustain large axial force, are pinned at each storey to avoid that also bending moment arise in these structural members. Instead, bending moment can be accepted in the gravity columns, because during the ground motion these members sustain gravity loads much smaller than those used for their design. A design procedure is proposed to estimate properly the bending moments in these columns. The procedure is based on two elastic analyses with numerical models that simulate the behaviour of the frame before and after yielding of the tensile braces. Braces in compression are not included in the numerical model. The sum of the bending moments obtained by these two analyses provides the design value of the bending moment in the columns. Finally, equations for the evaluation of the axial force in the columns of the braced frame (alternative to those suggested in EC8) are derived on the basis of the limit analysis of the frame. Even though the technological suggestions and design procedures are here developed for frames with diagonal braces, in principle they can be extended also to other braced structures [11-16]. 
The proposed technological suggestions and design procedures are applied to two case study structures with diagonal braces. The structures are also designed according to EC8. Then, the seismic performance of these structures is investigated by nonlinear dynamic analysis. Finally, the analysed structures are compared in terms of cross-section area of columns and seismic performance. This comparison allows the assessment of the benefit obtained by the application of the proposed design procedure and the impact on the costs of the structure.

\section{DESIGN OF FRAMES WITH DIAGONAL BRACES ACCORDING TO EC8}

In buildings with concentric diagonal braces, the seismic force is resisted by a few braced frames while the other frames support gravity loads only. Members of braced frames (braces, beams and columns) are designed assuming that the horizontal forces mainly produce axial forces. In the following sections, the provisions given in EC8 for the design of diagonal braces are briefly summarised and the seismic performance of two case study frames designed according to EC8 is evaluated and discussed.

\section{Design Provisions of EC8 on Frames with Concentric Diagonal Bracings}

According to EC8, in frames with concentric diagonal bracings, braces are devoted to yield and dissipate energy during strong ground motions (dissipative elements), while beams and columns are expected to remain elastic (nondissipative elements). The design internal forces of braces are determined by means of an elastic analysis of the structure with a reduced seismic force. The design spectrum (which provides the reduced seismic force $V_{E d}$ ) is obtained by reducing the elastic spectrum, representative of reference ground motions having a $10 \%$ probability of exceedance in 50 years, by the behaviour factor $q$. The $q$-value stipulated in EC8 for frames with diagonal braces is equal to 4.0. The model adopted for the evaluation of the design internal forces is affected by the expected high slenderness of braces. In fact, diagonal braces are expected to buckle at a low level of the seismic force. Therefore, the usual choice is to include the sole braces in tension in the numerical model. Consistently, at any storey, the lateral strength $V_{R d}$ provided by a pair of diagonal braces is assumed to be equal to the horizontal component of the axial force in tension brace, which is assumed to be yielded, whereas the contribution of the brace in compression is ignored

$$
V_{R d}=A_{b} f_{y} \cos \theta
$$

In Equation (1), $A_{b}$ is the cross-section area of braces, $f_{y}$ is the nominal value of the yield stress of steel and $\theta$ is the angle of inclination of the brace with respect to the longitudinal axis of the beam. The minimum area of the crosssection of braces of the $i$-th storey is determined by equating the lateral strength $V_{R d, i}$ to the corresponding seismic design storey shear force $V_{E d, i}$. Then, the overstrength factor $\Omega_{i}$ of each storey is calculated as the ratio of the lateral strength provided by the braces to the demanded storey shear force. To limit the tendency of low-redundant structures to develop a storey collapse mechanism [14, 17-21] and to promote a more dissipative behaviour, it is suggested that the over- strength factor $\Omega_{i}$ of a single storey should not be much lower than that of other storeys [17, 22-25]. Specifically, EC8 requires that the difference between the maximum and minimum storey overstrength factors $\Omega$ of the dissipative members should be not greater than $25 \%$ (strength homogeneity condition) $[26,27]$. However, such design requirement is difficult to achieve. For this reason the use of braces with reduced cross-section at their ends has been suggested $[7,28]$.

Once the braces have been designed, the design internal forces of beams and columns of the braced frame are determined according to the capacity design criteria. The simplified equations given in EC8 [1] can be used and the design axial force $N_{E d}$ of beams and columns is calculated as follows

$$
N_{E d}=N_{E d, G}+1.1 \gamma_{o v} \Omega_{\min } N_{E d, E}
$$

where $N_{E d, G}$ and $N_{E d, E}$ are the axial forces provided by the gravity loads in the seismic design situation and by the seismic forces, respectively. The coefficient $\gamma_{o v}$ is the steel overstrength factor. Beams sustain only the bending moment caused by the gravity loads.

\section{Case Studies}

Two steel building structures with diagonal braces are designed. The structures are 4- and 8-storey high and have the plan layout shown in Fig. (1). The braced frames, which are located along the perimeter of the building, are designed to sustain the entire seismic force and all the connections are pinned. The numerical model adopted in the design phase is shown in Fig. (1). The gravity columns located along the perimeter of the building are indicated by the symbol CL and are oriented with their strong axes parallel to the vertical direction. The other gravity columns, labelled as CC columns, are oriented with their strong axes parallel to the horizontal direction. Both these columns are not included in the model adopted for the evaluation of the effects of the seismic force.

The effects of the seismic force are determined by modal response spectrum analysis. The storey mass is calculated assuming that the design load for seismic design situation is $g_{k}+0.3 q_{k}=5.0 \mathrm{k} \mathrm{N} / \mathrm{m}^{2}$, being the dead and live loads $g_{k}$ and $q_{k}$ equal to 4.4 and $2.0 \mathrm{k} \mathrm{N} / \mathrm{m}^{2}$, respectively. The elastic spectrum proposed in EC8 for soil type C, characterised by a peak ground acceleration $a_{g, R}$ equal to $0.35 \mathrm{~g}$, and reduced by the behaviour factor $q=4$ is used. Braces in compression are not included in the numerical model. Nodes of the same floor are constrained to have the same horizontal displacement.

Steel grade S235 $\left(f_{y}=235 \mathrm{MPa}\right)$ is used for braces and the area of the cross-section of braces is determined at each storey by equating the storey shear force obtained by the modal response spectrum analysis to the storey shear strength calculated by Equation (1). Idealised cross-sections are used for the braces. Owing to this, braces are characterised by a cross-section area which is exactly equal to that required in design and fulfil the strength homogeneity condition of EC8. Only the braces of the upper storey of the 8storey frame have been slightly oversized $(\Omega=1.14)$ to satisfy the requirement of EC8 on the maximum normalized slenderness $(\bar{\lambda} \leq 2)$. 

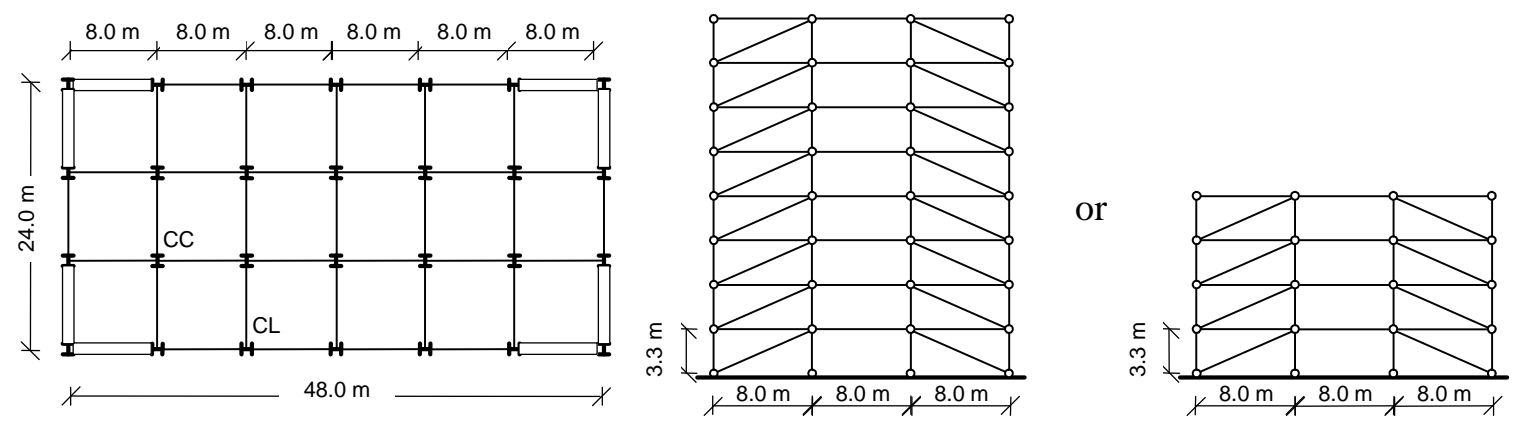

Fig. (1). Plan layout of the analysed structures and geometric model of the braced frame used in design.

Wide-flange shapes are used for the columns of the braced frames and for the gravity columns. Columns of the 4 -storey braced frame are steel grade S235. Instead, steel grades S235 and S275 $\left(f_{y}=275 \mathrm{MPa}\right)$ are used for the 4 upper storeys and for the 4 lower storeys of the 8 -storey braced frame, respectively. As all the beam-to-column connections are pinned, columns do not sustain any bending moment. The design axial force of the columns of the braced frame are determined by Equation (2). In this equation the material overstrength is not considered and the coefficient $\gamma_{o v}$ is assumed equal to unity to make the yield stress of braces assumed in design consistent with that adopted in the numerical analyses. Instead, the design axial force of the gravity columns is evaluated according to the tributary area concept and assuming that in the non-seismic situation the load per square meter is equal to $1.4 g_{k}+1.5 q_{k}=9.2 \mathrm{kN} / \mathrm{m}^{2}$. The minimum required crosssection area of the columns is obtained by equating their axial force to their buckling resistance, the latter being evaluated according to Eurocode 3 (EC3) [29] assuming $\gamma_{M I}=1.0$. At each storey, the largest cross-section area is adopted for all the columns of the braced frame (Fig. 1). Different cross-sections are used for CC- and CL-type gravity columns. Finally, the same structural member is used for the columns of two consecutive storeys because the storey height of the analysed buildings is relatively low $(3.3 \mathrm{~m})$.

\section{SEISMIC PERFORMANCE OF FRAMES DESIGNED BY EC8}

The seismic response of the two building structures with diagonal bracings designed according to EC8 is determined by nonlinear dynamic analysis for different seismic excitation levels and the seismic performance is evaluated for all the structural members. Finally, the maximum seismic excitation level that the structure can sustain is determined.

\section{Modelling of the Frames}

Two-dimensional models are used for the numerical analyses because the structures are symmetric. The adopted structural model includes one braced frame and three columns pinned at the base (Fig. 2) representing CC-type columns, CL-type columns and the columns belonging to the braced frame in the orthogonal direction (CB-type columns), respectively. The storey mass is equal to half of the mass of the deck. In this numerical model, only braces are allowed to yield and buckle. Beams, columns of the braced frame and gravity columns are modelled by elastic beam-column elements. This modelling allows the evaluation of the resistance required by the ground motion to these members. Braces are modelled by two beam elements with plastic hinges at their ends (Fig. 3a). The cross-sectional area of the beam element is that obtained by the brace design, while the radius of gyration $i_{b}$ and the plastic modulus $W_{p l, b}$ of the cross-section are calculated as a function of $A_{b}$

$i_{b}=0.0724 A_{b}+2.7082$

$W_{p l, b}=0.060 A_{b}^{2}+3.446 A_{b}-18.272$

These equations are representative of braces with square hollow cross-sections and are derived in [10]. The numerical model adopted for the braces can reproduce accurately the brace hysteretic behaviour (Fig. 3b) [30-36]. Details regarding the brace modelling can be found in [10] and in the paper by Tada and Suito [37]. A Rayleigh viscous damping is used and set at $3 \%$ for the first two modes of vibration. $P-\Delta$ effects are included in the analysis. All the columns are considered continuous for the whole height of the building (see Fig. 3). This configuration is the most penalizing for columns [21].

\section{Seismic Excitation}

The selection of ground motions is a key issue in seismic engineering. Some authors suggest using artificially generated accelerograms while some others use natural ground motions [38-40]. In this paper, five sets of natural ground motions are used to simulate earthquakes with different seismic excitation levels. The first one consists of 20 ground motions having a probability of exceedance of $10 \%$ in 50 years in the Los Angeles area. These records were adopted in the FEMA/SAC project in the United States [41]. Their intensity is scaled as reported in [10]. The other four suites are representative of higher seismic excitation levels and are characterised by lower probabilities of exceedance in 50 years, namely $5 \%, 4 \%, 3 \%$ and $2 \%$. In accordance with EC8, the peak ground accelerations of these ground motions are obtained by means of the following equation

$a_{g}=\left(\frac{P_{L, R}}{P_{L}}\right)^{1 / 3} a_{g, R}$

where $a_{g}$ is the peak ground acceleration of the suite of the scaled ground motions with probability of exceedance equal to $P_{L}$ in 50 years and $P_{L, R}$ is the probability of exceedance of the reference seismic action $(10 \%)$ in 50 years. The ratios $a_{g} / a_{g, R}$ obtained for probabilities of exceedance equal to $5 \%, 4 \%, 3 \%$ and $2 \%$ are $1.26,1.36,1.49$ and 1.71 , respectively. 

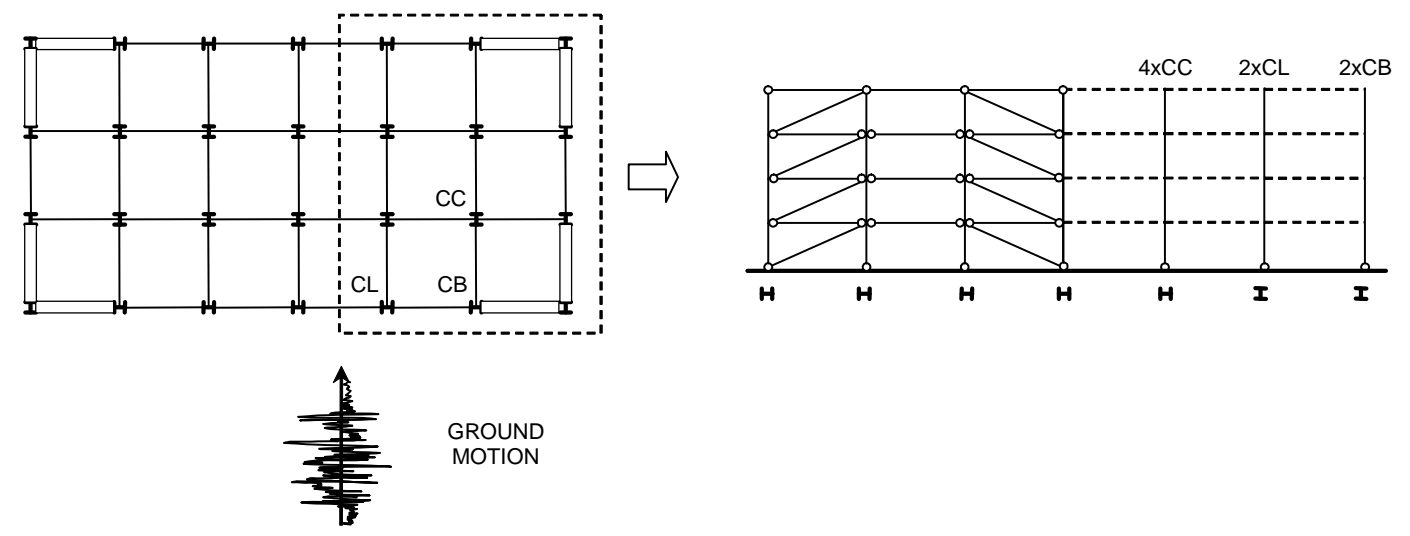

Fig. (2). Numerical model of the analysed structures.

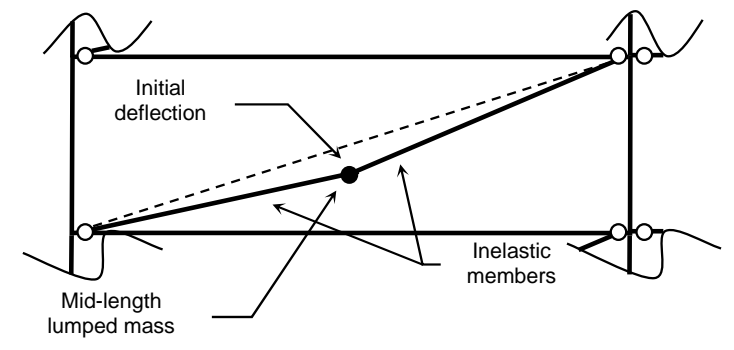

(a)

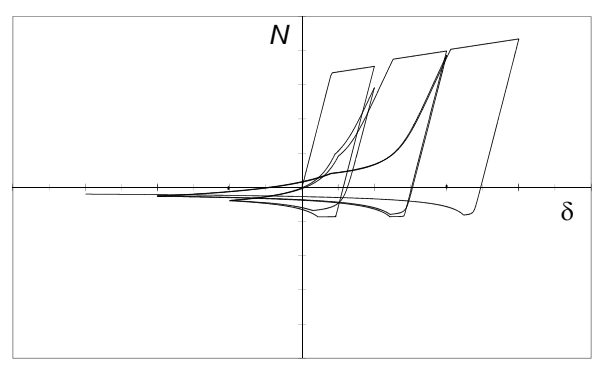

(b)

Fig. (3). Modeling of the brace: (a) numerical model, (b) hysteretic behaviour.

\section{Results of Numerical Analyses}

The seismic performance of the analysed structures is expressed in terms of the ductility demand of braces and in terms of the required resistance of non-dissipative members. The required ductility and resistance are normalized to the corresponding capacities. The maximum ductility demand $\mu$ of the braces is calculated as the ratio of the sum of the maximum shortening and elongation experienced by the brace during the earthquake (both being taken as absolute values) to the axial elongation of the brace at the brace yielding $\delta_{y}$. Then, the ratio $\bar{\mu}$ of the ductility demand $\mu$ to the ductility capacity of the brace under cyclic loading $\mu_{f}$ provides the seismic performance of the frame in terms of the brace ductility demand. The ductility capacity of the braces $\mu_{f}$ is determined by the equation derived in [10].

$\mu_{f}=1+\theta_{f}^{2} \frac{E}{2 f_{y}}$

where $E$ is the Young's modulus of steel and $\theta_{f}$ is the rotation of the end cross-section of the brace at fracture. This rotation is evaluated as a function of the brace slenderness ratio $\lambda$ and width-to-thickness ratio of the walls of the crosssection $d / t$ as given by the following relation.

$\theta_{f}=0.091\left(\frac{d}{t}\right)^{-0.2} \lambda^{0.3}$

Equation (7) was calibrated by Tremblay et al. based on the response of a large set of braces [42]. Values of $\bar{\mu}$ greater than 1 are representative of an unacceptable performance of braces. Beams, columns of the braced frame, and gravity columns are subjected to axial compression $N$ and uniaxial bending moment $M$. The buckling of these members does not take place if

$\max \left\{\begin{array}{l}\frac{N}{N_{b, R d, y}}+k_{y y} \frac{M}{M_{R d, y}} \leq 1 \\ \frac{N}{N_{b, R d, z}}\end{array}\right.$

bending about the strong $(y)$ axis

$\frac{N}{N_{b, R d, z}}+k_{z z} \frac{M}{M_{R d, z}} \leq 1$

bending about the weak $(z)$ axis

More details about Equations (8) and (9) and about the meaning of the symbols in these equations can be found in [10] and in Annex B of EC3 [29]. Similarly, according to the resistance criteria stipulated in EC3, yielding of nondissipative members is avoided if

$$
\begin{cases}\frac{M}{M_{R d, y}} \leq 1 & \text { :for } \frac{N}{N_{R d}} \leq 0.5 a \\ \frac{N}{N_{R d}}+(1-0.5 a) \frac{M}{M_{R d, y}} \leq 1 & \text { :for } \frac{N}{N_{R d}}>0.5 a\end{cases}
$$

bending about the strong (y) axis

$\begin{cases}\frac{M}{M_{R d, z}} \leq 1 & \text { :for } \frac{N}{N_{R d}} \leq a \\ \left(\frac{N / N_{R d}-a}{1-a}\right)^{2}+\frac{M}{M_{R d, z}} \leq 1 & \text { : for } \frac{N}{N_{R d}}>a\end{cases}$

bending about the weak $(z)$ axis 
where $a$ is the ratio of the web area to the gross area of the cross-section.

The buckling resistance of beams is calculated assuming that buckling about the weak axis is restrained by the deck. The maximum values provided by Equations (8) and (9) and by Equations (10) and (11) over the entire duration of the earthquake are taken as the indexes of seismic performance and are called hereinafter stability $(S I)$ and resistance $(R I)$ index, respectively.

\section{Discussion on Results}

Referring to the systems designed according to EC8, the heightwise distribution of the normalized ductility demand and that of the stability and resistance indexes are represented in Figs. (4-6). Different curves are reported in each figure. Each curve refers to the seismic response to a seismic event with an assigned probability of exceedance in 50 years. The ductility demand on braces (Fig. 4) does not exceed the corresponding capacity if seismic events characterised by a probability of exceedance not lower than $3 \%$ in 50 years are considered. Instead, the maximum normalized ductility demand is slightly higher than unity in the case of the rarest considered seismic events.

Fig. (5) shows that both the stability and resistance indexes of the columns are exceeded. These results are in agreement with those presented in $[8,10,19,28]$ where the failure of columns in CBFs designed according to EC8 is pointed out. Specifically, the columns belonging to the 8storey braced frame do not fulfil the stability requirement even if seismic events with $10 \%$ probability of exceedance are considered. Indeed, these columns are subjected not only to high axial forces but also to significant bending moments, which mainly develop after brace yielding. The axial forces of the CC-type columns, instead, are only due to gravity loads acting in the non-seismic design situation and thus this internal force is surely well predicted in the phase of design. Nevertheless, both the stability and the resistance indexes are higher than unity for seismic events with a probability of exceedance of $5 \%$ in 50 years. This unsatisfactory behaviour is due to the high value of the seismic bending moments, which are not predicted by means of a standard design method of analysis. Finally, the CL-type columns satisfy both the stability and resistance requirements. Similarly to the CC-type columns, these columns are subjected to con- stant axial force. However, only low values of the bending moment act on these columns because of the in-plan orientation of their cross-section. Similar considerations apply to the 4-storey structure, as shown in Fig. (6).

Owing to these results, the maximum seismic excitation level that the structures can sustain is well below that corresponding to the brace fracture $(5 \%$ or $10 \%$ instead of $3 \%$ probability of exceedance in 50 years).

\section{PROPOSALS FOR DESIGN OF COLUMNS}

As reported in the previous section, both columns of the braced frame and gravity columns experienced yielding or buckling for a seismic excitation level lower that that corresponding to the fracture of braces. This is because columns are designed to sustain only axial force whereas their seismic response is significantly aggravated by bending moment. Further, in the case of the columns of the braced frame, Equation(2) given in EC8 may underestimate their axial force $[8,19,28]$. In the following sections different solutions are given to improve the seismic performance of columns of the braced frame and that of gravity columns. In particular, the proposed design criteria aim to avoid yielding and/or buckling of columns prior to brace fracture.

\section{Columns of the Braced Frame}

The axial force of the columns of the braced frames is generally high. Therefore, a large cross-section is usually required. If the size of the columns was made bigger to sustain also significant bending moments, it would become too large. Based on this consideration, it is suggested that columns of the braced frames are pinned at their ends. If this structural configuration is adopted, columns of the braced frame will not experience any bending moment during the earthquake. Although an ideal pinned connection is not simple to realize from a technological point of view, the adoption of a semi-rigid connection characterised by a low value of the stiffness could be useful to reduce significantly the bending moments on these columns.

As regards the evaluation of the design axial force, an approach that is alternative to the use of Equation (2) is proposed. This approach is similar to that described by Tremblay and Robert [43] for chevron braced frames. In particular, Tremblay and Robert evaluate the design internal

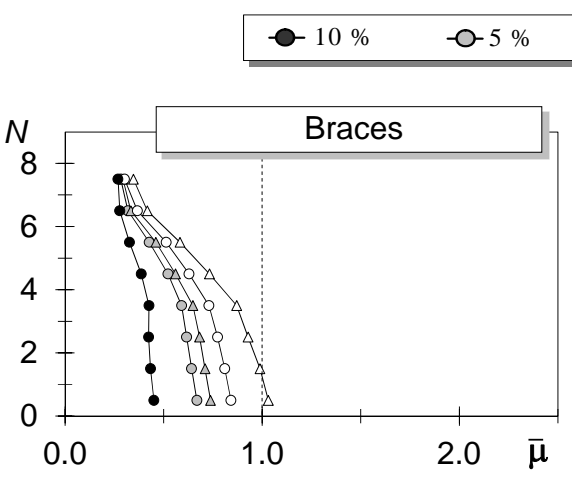

(a)

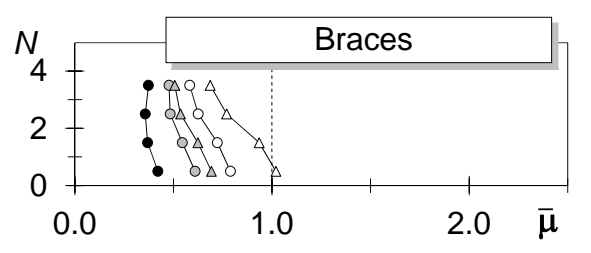

(b)

Fig. (4). Normalised ductility demand of the braces for seismic events with different probability of exceedance (a) 8-storey structures and (b) 4-storey structures. 


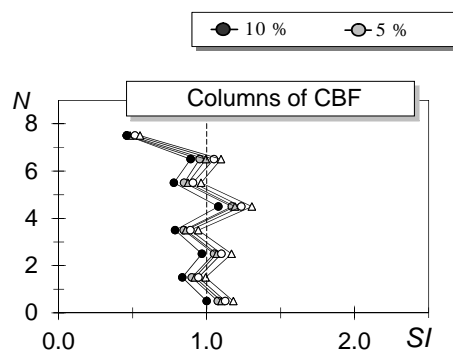
$\triangle 4 \% \quad-0-3 \% \quad-\triangle 2 \%$
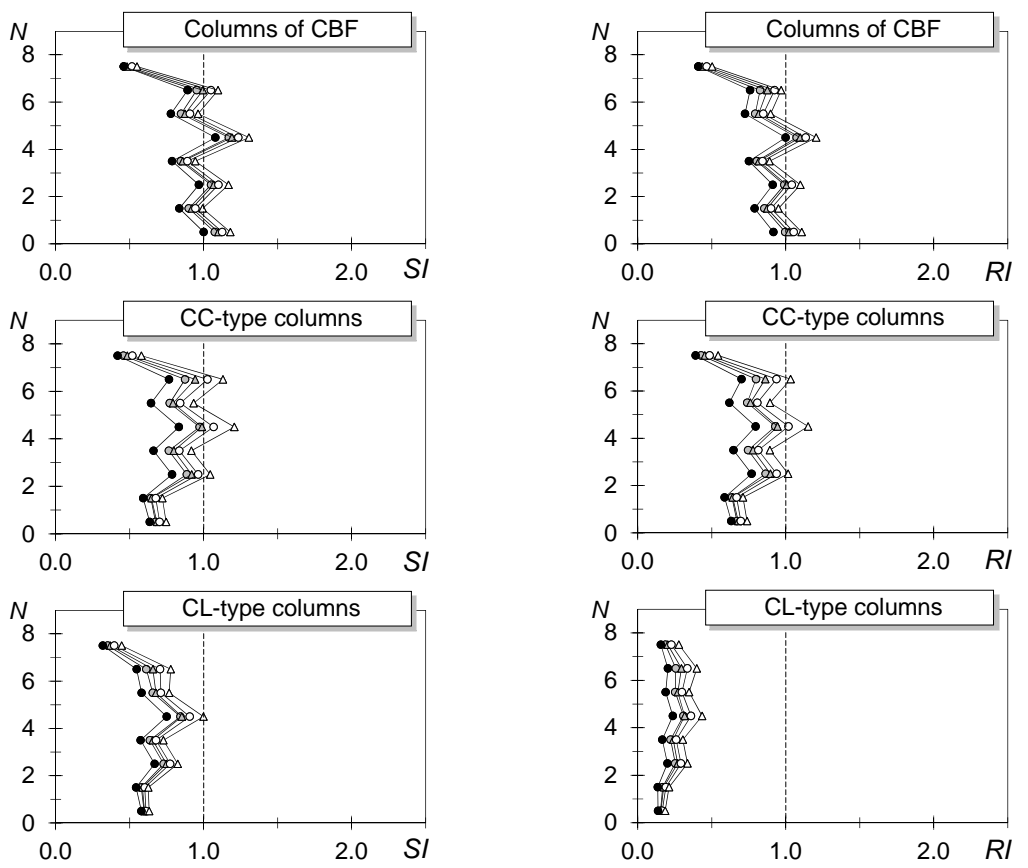

Fig. (5). Buckling and yielding indexes of the columns of the 8-storey structure for seismic events with different probability of exceedance.

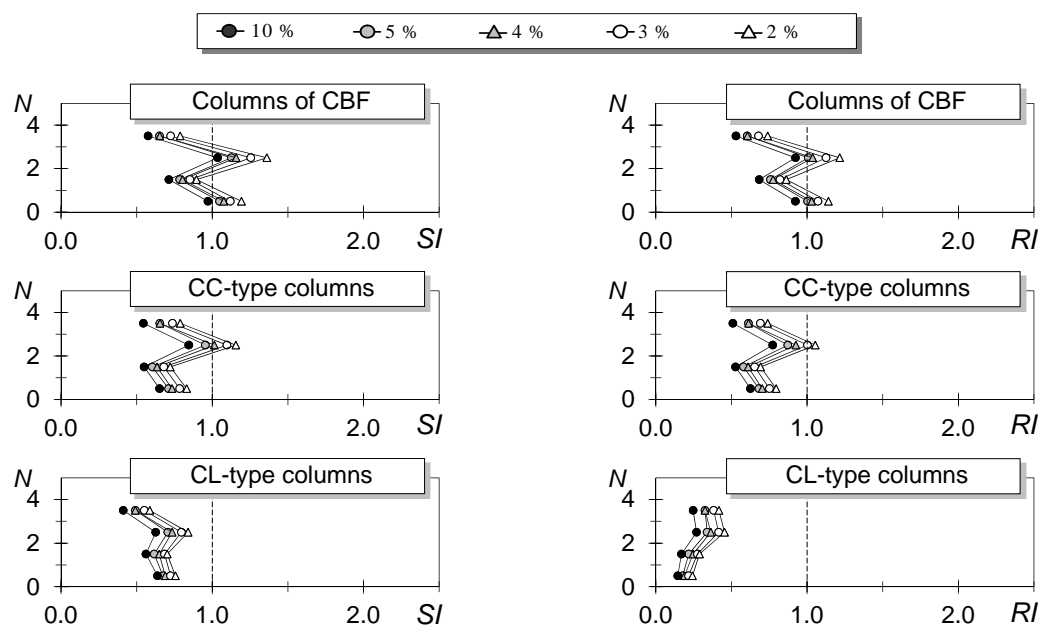

Fig. (6). Buckling and yielding indexes of the columns of the 4-storey structure for seismic events with different probability of exceedance.

forces of non-dissipative members by equilibrium of the frame when two limit states are reached. In the first limit state, all the braces in compression transmit the buckling axial forces (Fig. 7a); in the second limit state, all the braces in tension are yielded and hardened while those in compression are in the post-buckling range of behaviour (Fig. 7b). This approach may also be applied to frames with diagonal braces. A summary of the equations necessary to evaluate the design axial forces of the columns follows. A superscript " $b$ " is added to identify the parameters of the first limit state, while a superscript " $y$ " is used for the second limit state. The force transmitted by the yielded tension brace is equal to its plastic resistance amplified by coefficients 1.1 and $\gamma_{o v}$. The first coefficient (1.1) takes into account the hardening of the material while the second $\gamma_{o v}$ considers the overstrength of the material. Consistently, the buckling and post-buckling resistances of the braces are amplified by the sole coefficient $\gamma_{\text {ov. }}$.

The first limit state causes the most severe situation for the external columns whereas the second causes the most severe situation for the internal columns (Fig. 7). The design axial force of the internal column at the $i$-th storey is obtained by the vertical equilibrium represented in Fig. 8a assuming that the tension braces are yielded

$$
N_{c o l, i}^{y}=\sum_{j=i}^{N}\left(P_{j}+V_{b e a m, G, j}+1.1 \gamma_{o v} N_{y, j} \sin \theta\right)
$$




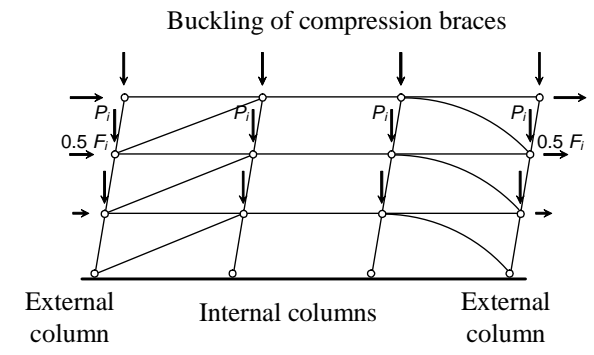

(a)

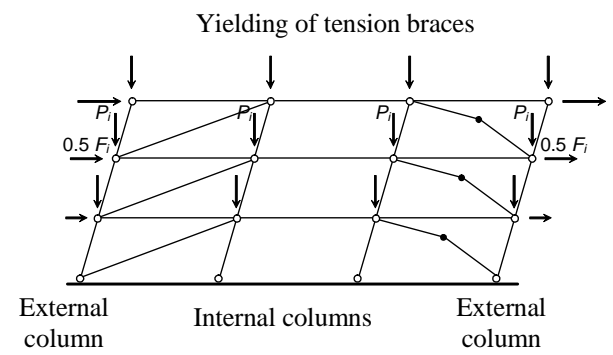

(b)

Fig. (7). Limit states considered for design of columns: (a) incipient buckling of compression braces and (b) yielding of tension braces and compression braces in post-buckling regime.

In this Equation, $P_{j}$ is the gravity force acting on the column of the $j$-th storey in the seismic design situation and $V_{\text {beam, }, j, j}$ is the total shear force transmitted by the adjacent beams. The shear force of each beam is calculated as half the gravity load acting on the beam in the seismic design situation. Instead, the design axial force of the external column at the $i$-th storey is evaluated by the vertical equilibrium represented in (Fig. 8b) assuming that the force transmitted by each compression brace is equal to its buckling resistance $N_{c o l, i}^{b}=\sum_{j=i}^{N}\left(P_{j}+V_{\text {beam }, G, j}\right)+\gamma_{o v} \sum_{j=i+1}^{N} N_{b, j} \sin \theta$

\section{Gravity Columns}

During the earthquake, the value of the gravity load is that corresponding to the seismic design situation and, thus, it is much smaller than that used for the design of gravity columns (gravity load in non-seismic design situation). Therefore, gravity columns sustain an axial force which is much smaller than that used in design and can resist significant bending moments before yielding or buckling is reached. Based on this consideration, it is suggested that gravity columns are continuous along the height of the building. In fact, the presence of continuous columns has a beneficial effect on the redistribution of the plastic deformation of braces [44-53]. However, the bending moments that arise in gravity columns during ground motions have to be determined and considered.

If all the braces of the frame are in the elastic range of their behaviour, the seismic force provides a displacement profile that is almost linear. As an example, Fig. (9a) shows the horizontal displacement profile of the 8-storey frame analysed in the previous Section assuming that all the braces are elastic. The horizontal displacements are determined by modal response spectrum analysis and by means of the CQC combination rule. Since gravity columns basically rotate rigidly about their base, the bending moments are negligible. When the braces of some storeys yield, their stiffness drops to zero and the horizontal displacement profile changes significantly. As an example, Fig. (9b) shows the shape of the horizontal displacement profile when the braces of the three lower storeys are removed to simulate the response of the frame after their yielding. In the figure the horizontal displacements are scaled to obtain the same top displacement. In this case, the gravity columns are significantly deformed in flexure and sustain large bending moments.
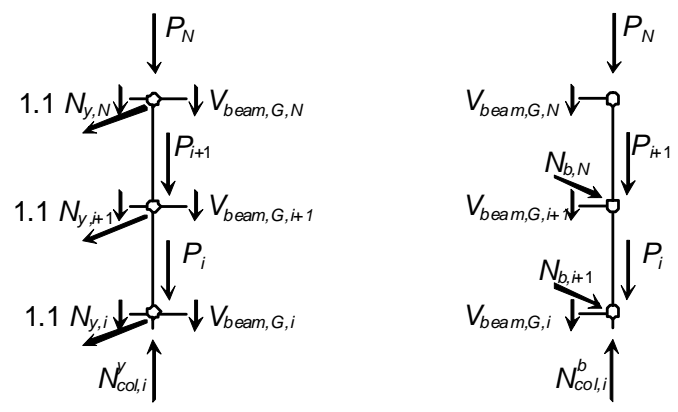

(a)

Fig. (8). Evaluation of design axial force: (a) internal column and (b) external column.

Based on this consideration, the bending moments acting on the gravity columns at brace fracture are calculated by adding the contributions corresponding to two different stages of behaviour of the braced frame. The two contributions are evaluated by elastic numerical models. The first stage of behaviour is characterised by axial forces of braces that are lower than their plastic resistance. Therefore, in the first numerical model all the braces in tension are elastic. The braces in compression are not included in the numerical model because it is assumed that they buckle for very low seismic excitation level. It is important to note that this numerical model is that suggested in EC8 for the design of diagonal bracings. The structure is subjected to the design seismic forces, determined by the design spectrum, which cause the yielding of braces and lead the frame to the beginning of the successive range of behaviour. The response quantities determined by this numerical model are indicated by means of the superscript " 1 ".

In the second range of behaviour, it is assumed that the braces of some storeys have yielded. Even though braced frames are prone to develop a storey collapse mechanism, it is unlikely that only the braces of one storey yield. Indeed, because of the presence of the continuous gravity columns, internal forces increase once the storey collapse mechanism has originated and also braces of other storeys yield. Here, it is assumed that braces yield at the storeys below and above the storey where the collapse mechanism has originated. The numerical model simulating the frame in the second stage of behaviour is obtained by removing the braces that are assumed to have yielded. The three storeys where the braces 
(a)

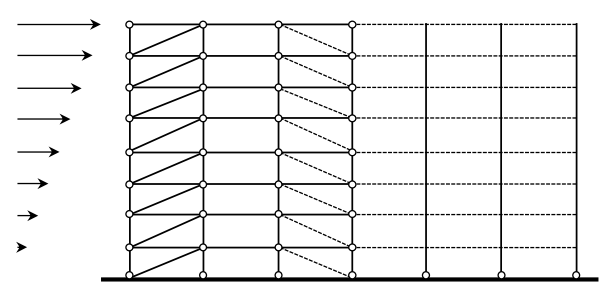

Analysis stage 2

(b)

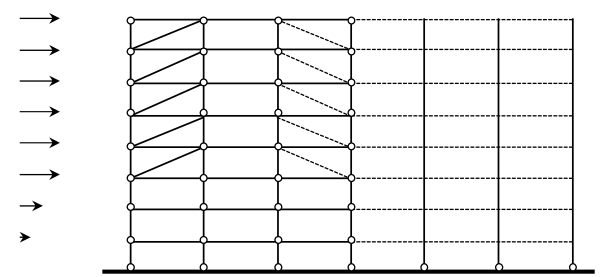

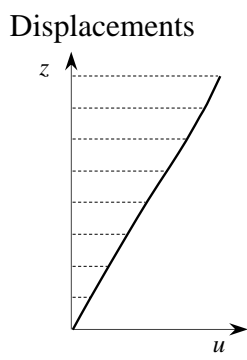

Bending moment
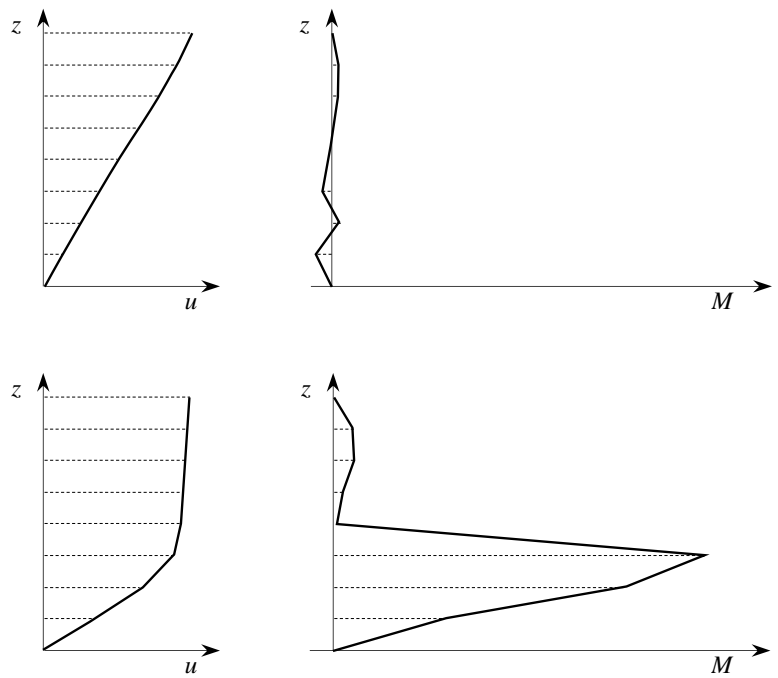

Fig. (9). Idealised stages of behaviour of the braced frame: (a) before yielding and (b) after yielding of braces.

are removed are shifted along the height of the frame because the storey where the collapse mechanism initiates is not known a priori. Owing to this, in the second stage of behaviour, $N$ numerical models are obtained for an $N$-storey frame (Fig. 10). The response quantities determined by these numerical models are indicated by means of the superscript "2,i", where " $i$ " identifies the storey where the collapse mechanism has identifies.

The total response of the frame subsequent to brace yielding at the $i$-th storey can be obtained as the response to vertical load $G$, plus the response of the first numerical model subjected to the seismic design force $E^{(1)}$, plus $\gamma_{i}$ times the response of the second numerical model (where the braces of the storeys $i-1, i$ and $i+1$ are removed) subjected to a reference seismic force $E^{(2, i)}$ determined by the elastic response spectrum. The coefficient $\gamma_{i}$ is introduced because the second numerical model is valid while the axial elongation (or shortening) demand $\delta_{j}$ of the braces of each storey $(j=1$ to $N$ ) is not higher than the corresponding capacity $\delta_{j}^{\max }$. Thus, the coefficient $\gamma_{i}$ is an index of the extent of plastic deformation of braces. If $\gamma_{i}=0$, the response obtained is that corresponding to the achievement of the first yielding; instead, if $\gamma_{i}>0$, the response obtained is that corresponding to a given plastic deformation of the braces. To evaluate the coefficient $\gamma_{i}$, the axial elongation demands $\delta_{j}^{(1)}$ and $\delta_{j}^{(2, i)}$ of the braces of the $j$-th storey are determined first by the analysis of the numerical models for stage 1 and stage 2, respectively. Specifically, the axial elongation demands are determined as the difference between the original length of the brace and the length of the brace in the deformed shape. Second, the value of $\gamma_{i}=\gamma_{i, j}{ }^{\max }$ that leads to the fracture of the braces of the $j$-th storey, is determined by equating the axial elongation demand of the braces $\delta_{j}$ (given by $\delta_{j}^{(1)}+\gamma \delta_{j}^{(2, i)}$ ) to the elongation capacity $\delta_{j}^{\max }$

$\gamma_{i, j}^{\max }=\frac{\delta_{j}^{\max }-\delta_{j}^{(1)}}{\delta_{j}^{(2, i)}}$

The axial elongation capacity of the braces is evaluated here as $\delta_{j}^{\max }=0.5 \mu_{j}^{f} \delta_{j}^{y}$

where $\delta_{j}^{y}$ is the elongation of the brace at yield. The coefficient $\gamma_{i, j}{ }^{\text {max }}$ must be calculated for all the storeys and the minimum value $\gamma_{i}^{\min }=\min \left(\gamma_{i, j}^{\max }\right)$ is that corresponding to the first fracture of the braces. If yielding of the braces initiates at the $i$-th storey, the bending moment $M_{i, j}$ of the columns at the first brace fracture is given by the following equation

$M_{i, j}=M_{G, j}+M_{E, j}^{(1)}+\gamma_{i}^{\min } M_{E, j}^{(2, i)}$

and the design bending moment is given as

$M_{E d, j}=\max \left(M_{i, j}\right) \quad i=1,2, \ldots, N$

\section{INFLUENCE OF THE PROPOSED DESIGN OPTIONS ON THE CASE STUDY FRAMES}

The two case study frames represented in (Fig. 1) have been designed according to the proposed design options. In order to separate the influence of each proposed modification, four alternatives are analysed and compared.

1. In the first alternative, the frames are those designed according to EC8 and analysed in the previous sections. All the columns are continuous for the whole height of the building. This configuration is expected to promote a more uniform distribution of the normalized ductility demand of the braces.

2. In the second alternative, the connections at the ends of the columns of the braced frames are pinned. The gravity columns are continuous but are designed to sustain gravity loads only. The cross-sections of all the members are those assigned in the previous design alternative and only the numerical model adopted for the nonlinear dynamic analysis is different.

3. In the third alternative, the connections at the ends of the columns of the braced frames are pinned and the gravity columns are designed to sustain axial forces and bending moments. 
4. The fourth alternative differs from the third because the design axial forces on the columns of the braced frame are evaluated by means of the Equations (12) and (13) based on limit equilibrium conditions.

The column cross-section areas and the seismic performance of the structures designed by means of the abovementioned four design alternatives are compared in the following Sections.

\section{Column Cross-Sections}

Fig. (11) compares the area of the cross-sections adopted for the columns of the considered alternative frames. Column sections adopted at the same storey can be of different steel grades if the frames are designed according to different design options. For this reason, at each storey the area of the cross-section is scaled by the correction factor $f_{y} / 235$, where $f_{y}$ is the yield stress of the steel expressed in MPa. White bars represent the area of the cross-sections adopted when the first and the second alternative designs are considered. Grey and black bars represent the cross-section areas corresponding to the two other alternative designs. The figure shows that the adoption of the third alternative leads to an increase in the area of the cross-section of the CC-type columns, i.e. of the columns that provide the maximum flexural stiffness. The increase in the area of the cross-section of the CL-type columns, instead, is null in the case of the 4storey frame and low in the case of the 8-storey frame. Finally, the evaluation of the axial forces on the columns of the braced frames by equilibrium conditions produces a slight increase in the cross-section area of these columns only at a few storeys of the 8-storey structures. In fact, because of the adoption of idealised brace cross-section, the overstrength is generally equal to 1.0 and Equation (2) leads to axial forces close to those provided by the equilibrium conditions at the two considered limit states (Eqs. 12-13).

\section{Seismic Performance}

Figs. $(12,13)$ compare the seismic response of the frame designed according to the first alternative to that of the frames designed according to the other proposed alternatives. Specifically, results refer to seismic events with a probability of exceedance of $2 \%$ in 50 years. Four curves are compared. The first curve (white triangles) quantifies the heightwise distribution of the response parameters in the structure designed by the standard design procedure (first alternative).

Brace yielding initiates at:

$1^{\text {st }}$ storey, model $(2,1)$

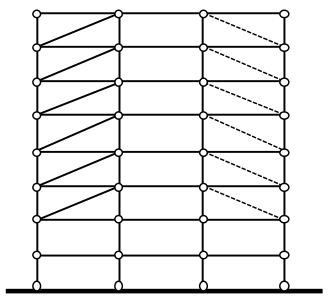

$2^{\text {nd }}$ storey, model $(2,2)$

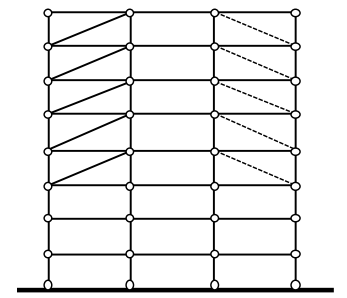

$\mathrm{N}^{\text {th }}$ storey, model $(2, \mathrm{~N})$

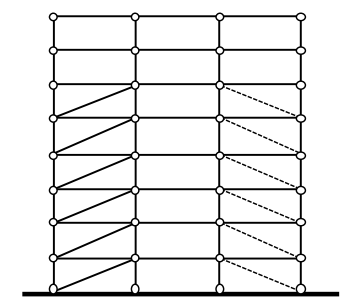

Fig. (10). Numerical models for stage 2 (gravity columns are included in the models even though are not shown in figure).

$\square 1^{\text {st }}, 2^{\text {nd }}$ design alternatives

$\square 3^{\text {rd }}$ design alternative

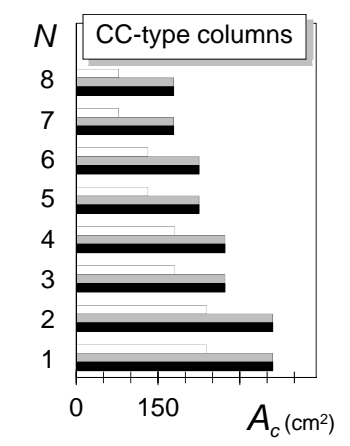

$A_{c}\left(\mathrm{~cm}^{2}\right)$
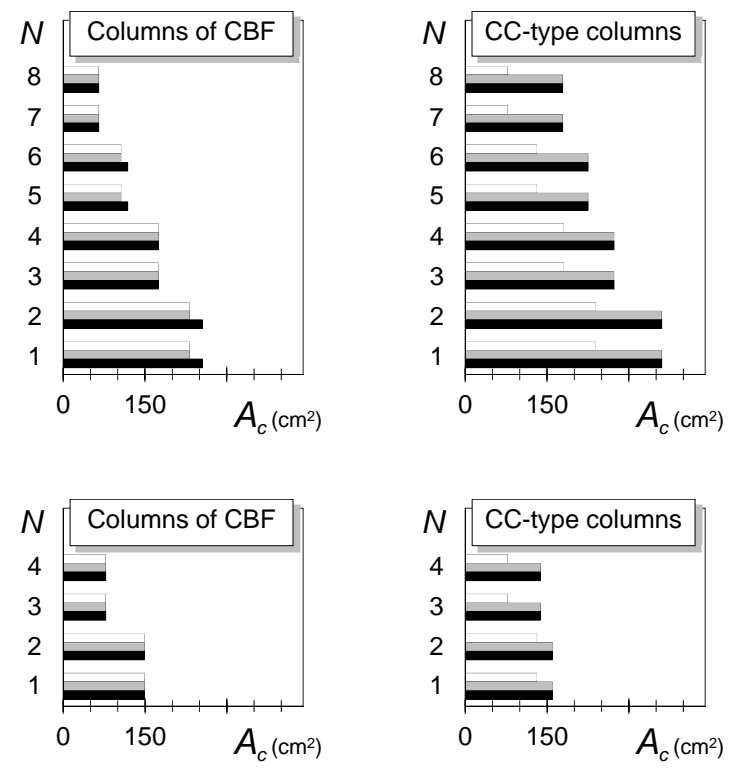

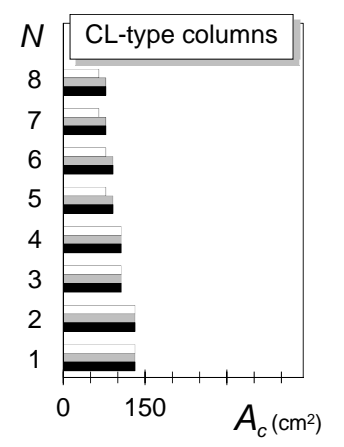

$4^{\text {th }}$ design alternative

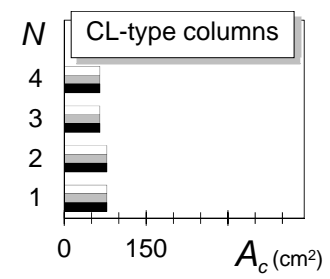

Fig. (11). Comparison of the area of the cross-section of the columns designed according to the considered alternatives. 

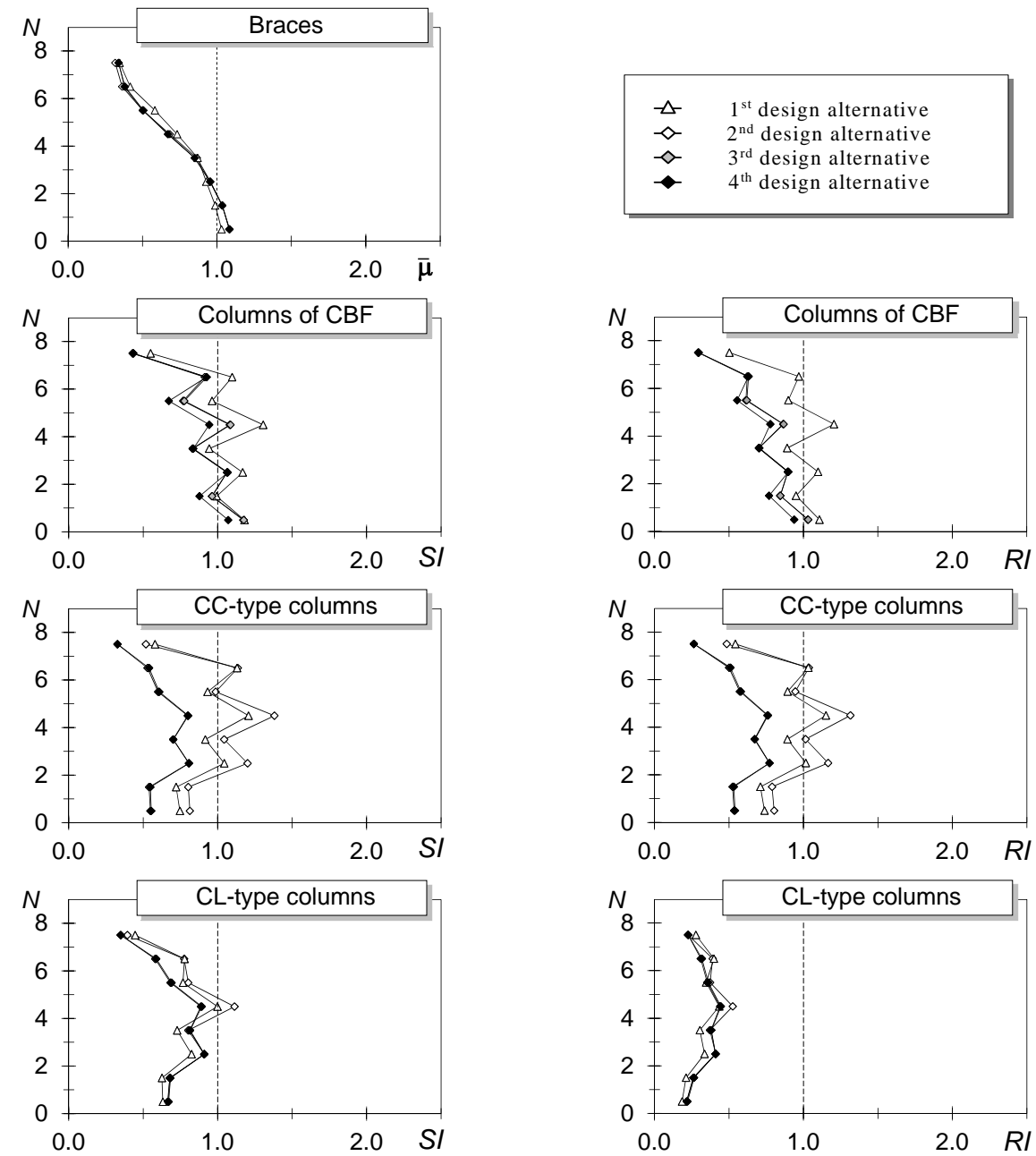

Fig. (12). Seismic performance of the 8 -storey structure for seismic events with probability of exceedance of $2 \%$ in 50 years.
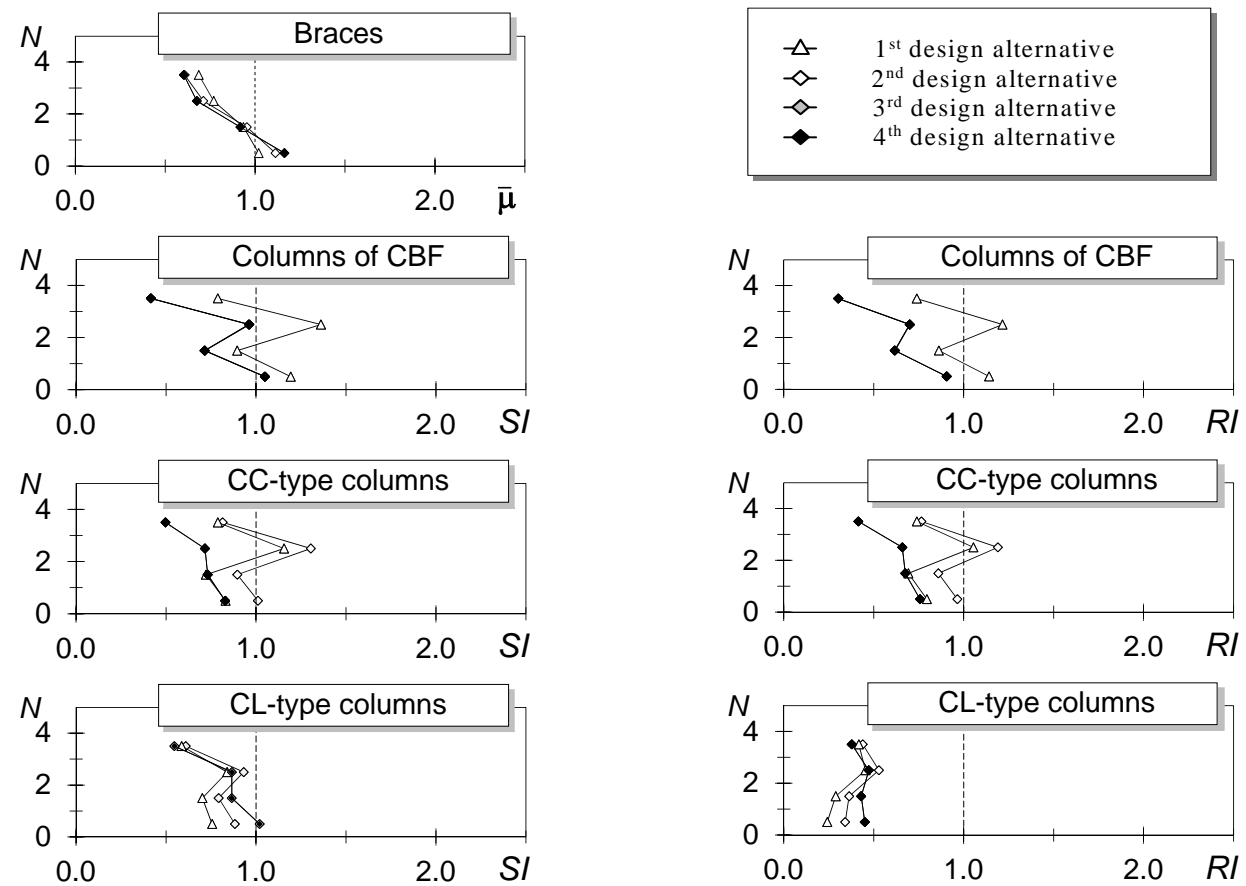

Fig. (13). Seismic performance of the 4 -storey structure for seismic events with probability of exceedance of $2 \%$ in 50 years. 
White rhombuses pinpoint the response of the same structure in which the columns belonging to the braced frame are supposed to be pinned at each storey (second alternative). Finally, grey and black rhombuses refer to the structures in which the columns of the braced frame are pinned and the gravity columns are designed to sustain bending moments (third and fourth alternative, respectively). The figures show that the introduction of the pinned connections in the columns of the braced frames produces a slight increase in the normalised ductility demand of the braces at the first two storeys and reduces significantly the values of the stability and resistance indexes of the columns of the braced frame. In fact, only internal axial force acts on these columns. However, at a few storeys these indexes are still larger than 1 . The evaluation of the design internal forces on these columns by limit analysis leads to a further reduction in the values of the two indexes.

Conversely, the values of the stability and resistance indexes of the other columns increase when the connections of the columns of the braced frames are pinned because bending moments are sustained only by the gravity columns. However, when the gravity columns are designed considering also the bending moments evaluated according to the proposed method, the above indexes reduce significantly and both the stability and resistance requirements are generally fulfilled.

\section{CONCLUSION}

The paper analyses the seismic response of concentrically braced structures with diagonal braces designed by a standard design procedure in compliance with capacity design principles. The results, obtained by nonlinear incremental dynamic analysis, show that both the columns of the braced frame and the gravity columns experience yielding and/or buckling for a seismic excitation level lower that that corresponding to the fracture of the braces. This is because, when the braces have yielded, the columns are significantly deformed in flexure and sustain large bending moments that are not predicted by standard design procedures.

To avoid yielding and/or buckling of columns prior to brace fracture the following design choices are suggested:

1. the columns of the braced frames should be pinned at their ends;

2. the gravity columns should be continuous along the height of the building; in fact, the presence of continuous columns has a beneficial effect on the redistribution of the plastic deformation of braces;

3. the bending moments on the gravity columns should be considered in design; in this regard, a design procedure is proposed to predict the bending moments of the gravity columns based on the results of two elastic analyses.

The seismic analysis of two case study frames shows that the proposed design procedure leads to a significant improvement in the seismic performance of both the columns of the braced frames and the gravity columns.

\section{CONFLICT OF INTEREST}

The authors confirm that this article content has no conflict of interest.

\section{ACKNOWLEDGEMENTS}

The Authors wish to thank Claudia Caruso and Melita Cristaldi for their contribution to the numerical analyses performed in the context of their graduation thesis.

\section{REFERENCES}

[1] Eurocode 8. Design of structures for earthquake resistance. European Committee for Standardisation 2003, prEN 1998-1-1/2/3.

[2] AIJ. Design standard for steel structures. Architectural Institute of Japan, Tokyo, 1973. (in Japanese)

[3] AIJ. Guidelines for limit state design of steel structures. Architectural Institute of Japan, Tokyo, 1998. (in Japanese)

[4] AISC. Seismic Provisions for Structural Steel Buildings. American Institute of Steel Construction: Chicago, 2002.

[5] E.M. Marino, M. Nakashima and K.M. Mosalam, "Comparison of European and Japanese seismic design of steel building structures", Engineering Structures, vol. 27, pp. 827-40, 2005.

[6] M. Tada, T. Fukui, M. Nakashima, and C.W. Roeder, "Comparison of strength capacity for steel building structures in the United States and Japan". Earthquake Engineering and Engineering Seismology, vol. 4, pp. 37-49, 2003.

[7] M.T. Giugliano, A. Longo, R. Montuori and V Piluso "Plastic design of CB-frames with reduced section solution for bracing members", Journal of Constructional Steel Research, vol. 66, pp. 611-21, 2010.

[8] A. Longo, R. Montuori, and V. Piluso "Failure mode control of Xbraced frames under seismic actions", Journal of Earthquake Engineering, vol. 12 no. 5, pp. 728-59, 2008.

[9] A. Longo, R. Montuori, and V. Piluso "Plastic design of seismic resistant V-braced frames", Journal of Earthquake Engineering, vol. 12 no. 8, pp. 1246-66, 2008.

[10] E.M. Marino, "A unified approach for the design of high ductility steel frames with concentric braces in the framework of Eurocode 8", Earthquake Engineering and Structural Dynamics, vol. 43 no. 1, pp. 97-118, 2014.

[11] M. Bosco and E.M. Marino, "Design method and behavior factor for steel frames with buckling restrained braces", Earthquake Engineering and Structural Dynamics, vol. 42 no. 8, pp. 1243-63, 2013.

[12] G. Brandonisio, M. Toreno, E. Grande, E. Mele, and A. De Luca, "Seismic design of concentric braced frames", Journal of Constructional Steel Research, vol. 78, pp. 22-37, 2012.

[13] G. Brandonisio, A. De Luca, E. Grande, and E. Mele, "Non-linear response of concentric braced frames", in Proceedings of the 5th International Conference on Behaviour of Steel Structures in Seismic Areas - STESSA 2006, pp. 399-405.

[14] E.M. Marino and M. Nakashima, "Seismic performance and new design procedure for chevron-braced frames", Earthquake Engineering and Structural Dynamics, vol. 35, pp. 433-52, 2006.

[15] K. Deng, P. Pan, A. Lam, and Y. Xue, "A simplified model for analysis of high-rise buildings equipped with hysteresis damped outriggers", The Structural Design of Tall and Special Buildings 2013; DOI: 10.1002/tal.1113.

[16] R. Tremblay, "Seismic behavior and design of concentrically braced frames", Engineering Journal AISC, vol. 38 n. 3, pp. 148$66,2001$.

[17] M. Bosco and P.P. Rossi, "Seismic behaviour of eccentrically braced frames", Engineering Structures, vol. 31 no. 3, pp. 664-74, 2009.

[18] M. Bosco, A. Ghersi, E.M. Marino and P.P. Rossi, "Prediction of the seismic response of steel frames with concentric diagonal bracings", The Open Construction and Building Technology Journal, vol. 7, pp. 118-28, 2013.

[19] A. Longo, R. Montuori, and V. Piluso "Influence of design criteria on the seismic reliability of X-braced frames", Journal of Earthquake Engineering, vol. 12, pp. 406-31, 2008.

[20] A. Longo, R. Montuori, and V. Piluso "Seismic reliability of Vbraced frames: influence of design methodologies", Earthquake Engineering and Structural Dynamics, vol. 38, pp. 1587-608, 2009. 
[21] R. Tremblay, "Achieving a stable inelastic seismic response for multi-story concentrically braced steel frames", Engineering Journal AISC, vol. 40 no. 2, pp. 111-29, 2003.

[22] M. Bosco, E.M. Marino and P.P. Rossi, "Influence of the brace overstrength on the seismic behavior of chevron braced frames", in Proceeding of the 6th International Conference STESSA 2009, Behaviour of Steel Structures in Seismic Areas, 2009, pp. 297-302.

[23] P.P. Rossi and A. Lombardo, "Influence of the link overstrength factor on the seismic behaviour of eccentrically braced frames", Journal of Constructional Steel Research, vol. 63, pp. 1529-45, 2007.

[24] M. Lacerte and R. Tremblay, "Making use of the brace overstrength to improve the seismic response of multistory split-X concentrically braced steel frames", Canadian Journal of Civil Engineering, vol. 33, pp. 1005-21, 2006.

[25] A. Zona, L. Ragni and A. Dall'Asta, "Sensitivity-based study of the influence of brace over-strength distributions on the seismic response of steel frames with BRBs", Engineering Structures, vol. 37, pp. 179-92, 2012.

[26] E.P. Popov, J.M. Ricles and K. Kasai, "Methodology for optimum EBF link design", in Proceedings of the 10th World Conference on Earthquake Engineering, pp. 3983-88, 1992.

[27] M. Bosco, E.M. Marino and P.P. Rossi, "Proposal of modifications to the design provisions of Eurocode 8 for buildings with split $\mathrm{k}$ eccentric braces”, Engineering Structures, vol. 61, pp. 209-23, 2014.

[28] M.T. Giugliano, A. Longo, R. Montuori, and V. Piluso "Seismic reliability of traditional and innovative concentrically braced frames", Earthquake Engineering and Structural Dynamics, vol. 40 no. 13, pp. 1456-74, 2011 .

[29] CEN. EuroCode 3: Design of steel structures - Part 1-1: General rules and rules for buildings, ENV 1993-1-1. European Committee for Standardization, Bruxelles, 2005.

[30] M. D’Aniello, A.G. La Manna, F. Portioli, and R. Landolfo, "Modelling aspects of the seismic response of steel concentric braced frames", Steel and Composite Structures, An International Journal, vol. 15 no. 5, 539-66, 2013.

[31] M. D’Aniello, A.G. La Manna, F. Portioli, and R. Landolfo, “The influence of out-of-straightness imperfection in Physical-Theory models of bracing members on seismic performance assessment of concentric braced structures", The Structural Design of Tall and Special Buildings, 2014, DOI: 10.1002/tal.1160.

[32] B.V. Fell; A.M. Kanvinde, A.M. ASCE; G.G. Deierlein, F. ASCE; and A.T. Myers, "Experimental Investigation of Inelastic Cyclic Buckling and Fracture of Steel Braces", Journal of Structural Engineering (ASCE), vol. 135, no. 1, pp. 19-32, 2009

[33] G. Metelli, "Theoretical and experimental study on the cyclic behaviour of X braced steel frames", Engineering Structures, vol. 46, pp. 763-73, 2013.

[34] T. Nonaka, "An Elastic-plastic Analysis of a Bar under Repeated Axial Loading”, International Journal of Solid Structures, vol. 9, pp. $569-80,1973$

[35] E.P. Popov, K. Takanashi and C.W. Roeder, "Structural Steel Bracing Systems: Behavior Under Cyclic Loading”, Report. No. UCB/EERC-76/17, Earthquake Engineering Research Center, University of California, Berkeley, 1976.

[36] P. Uritz, F.C. Filippou and S.A. Mahin, "Model for cyclic inelastic buckling of steel braces", Journal of Structural Engineering, vol. 134, no. 4, pp. 619-628, 2008.
[37] M. Tada, A. Suito, "Static and dynamic post-buckling behavior of truss structures", Engineering Structures, vol. 20, pp. 384-89, 1998.

[38] A. Ghersi, E.M. Marino and P.P. Rossi, "Static versus modal analysis: influence on inelastic response of multi-storey asymmetric buildings", Bulletin of Earthquake Engineering, vol. 5, no. 4, pp. 511-532, 2007.

[39] M. Bosco, A. Ghersi and E.M. Marino, "Corrective Eccentricities for assessment by the nonlinear static method of 3D structures subjected to bidirectional ground motions", Earthquake Engineering and Structural Dynamics, vol. 41, pp. 1751-73, 2012.

[40] W. Shi, P. Pan, L. Ye, Y. Xu, and C. Wang, "Skyline-based ground motion selection method for nonlinear time history analysis of building structures", Earthquake Engineering and Structural Dynamics, vol. 42, pp. 1361-73, 2013.

[41] P. Somerville et al, "Development of ground motion time histories for phase 2 of the FEMA/SAC steel project. SAC Background Document", Report No. SAC/BD-99-03, SAC Joint Venture, 555 University Ave., Sacramento, 1997.

[42] R. Tremblay, M.-H. Archambault, and A. Filiatrault, "Seismic response of concentrically braced steel frames made with rectangular hollow bracing members", Journal of Structural Engineering, ASCE; vol. 129, pp. 1626-36, 2003.

[43] R. Tremblay, and N. Robert, "Seismic design of low- and mediumrise chevron braced steel frames", Canadian Journal of Civil Engineering, vol. 27, pp. 1192-206, 2000.

[44] C. Ariyaratana and L.A. Fahnestock, "Evaluation of bucklingrestrained braced frame seismic performance considering reserve strength", Engineering Structures, vol. 33, pp. 77-89, 2011.

[45] M. Bosco and P.P. Rossi, "A design procedure for dual eccentrically braced systems: Analytical formulation", Journal of Constructional Steel Research, vol. 80, pp. 440-52, 2013.

[46] M. Bosco and P.P. Rossi, "A design procedure for dual eccentrically braced systems: Numerical investigation", Journal of Constructional Steel Research, vol. 80, pp. 453-64, 2013.

[47] F. D'Agostino, G. Brando and G. De Matteis, "Prestazione sismica di telai in acciaio protetti mediante dispositivi isteretici e viscosi", Costruzioni metalliche, ISNN 0010-9673, LIX, 2012.

[48] X. Ji, M. Kato, T. Wang, T. Hitaka and M. Nakashima, "Effect of gravity columns on mitigation of drift concentration for braced frames", Journal of Constructional Steel Research, vol. 65, pp. 2148-56, 2009.

[49] G.A. MacRae, Y. Kimura and C. Roeder, "Effect of column stiffness on braced frame seismic behaviour", Journal of Structural Engineering (ASCE), vol. 130, pp. 381-91, 2004.

[50] S. Kiggins and C.M. Uang, "Reducing residual drift of bucklingrestrained braced frames as a dual system", Engineering Structures, vol. 28, pp. 1525-32, 2006.

[51] Y. Kimura and G.A. MacRae, "Effect of column flexural characteristic on seismic behavior of braced frame with fixed column base", in Proceedings of the 5th International Conference on Behaviour of Steel Structures in Seismic Areas - Stessa 2006, pp. 437-43.

[52] P.P. Rossi, "A design procedure for tied braced frames", Earthquake Engineering and Structural Dynamics, vol. 36, pp. 2227-48, 2007.

[53] Q. Xie and L. Zhao, "Seismic behavior of dual system with buckling-restrained braces", Journal of Shenyang Jianzhu University, vol. 24 , pp. $221-25,2008$.

Received: September 09, 2014

Revised: October 03, 2014

Accepted: October 15, 2014

(C) Bosco et al.; Licensee Bentham Open.

This is an open access article licensed under the terms of the Creative Commons Attribution Non-Commercial License (http://creativecommons.org/licenses/by-nc/3.0/) which permits unrestricted, non-commercial use, distribution and reproduction in any medium, provided the work is properly cited. 